
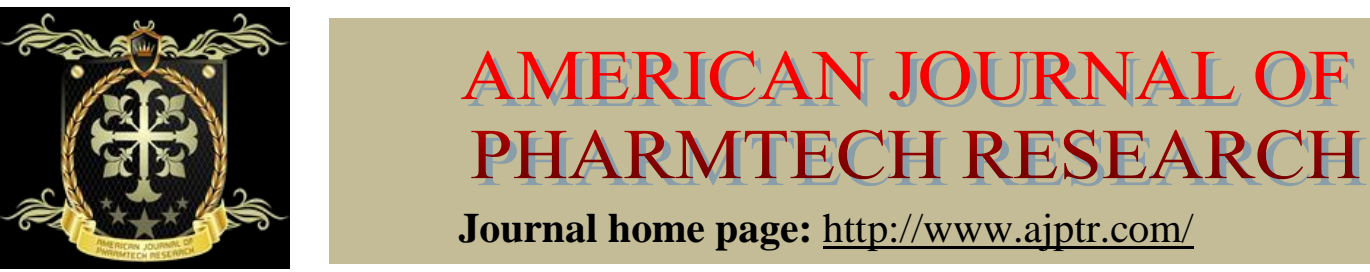

Journal home page: http://www.ajptr.com/

\title{
Rapid Determination of Loratadine Level in Human Plasma by LCMS/MS Assay
}

\author{
Rajaa F Hussein, Syed N Alvi, and Muhammad M Hammami* \\ Clinical Studies and Empirical Ethics Department, King Faisal Specialist Hospital \& Research \\ Center, MBC-03, P.O. Box 3354, Riyadh 11211, Saudi Arabia
}

\section{ABSTRACT}

A rapid liquid chromatographic tandem mass spectrometry (LC-MS/MS) assay for the measurement of loratadine level in human plasma was developed and validated. One ml plasma samples containing loratadine and $0.18 \mu \mathrm{g}$ of metoclopramide as (internal standard, IS) were extracted with $5 \mathrm{ml}$ tert-butyl methyl ether and reconstituted with $80 \mu \mathrm{l}$ of acetonitrile. Analysis was performed using a reversed phase Atlantis $\mathrm{dC}_{18}$ column and a mobile phase consisting of $0.4 \%$ formic acid and acetonitrile (20:80, v:v) and delivered at a flow rate of $0.25 \mathrm{ml} / \mathrm{min}$. The eluents were monitored using electrospray ionization in the positive ion mode with transition mass to charge ratio $(\mathrm{m} / \mathrm{z})$ at $383.4 \rightarrow 337.2$ and $299.8 \rightarrow 226.9$ for loratadine and IS, respectively. The retention times of the IS and loratadine were around 1.53 and $2.33 \mathrm{~min}$, respectively. Mean matrix effect was measured as $-11.4 \%$ for loratadine and $-14.4 \%$ for the IS. Detection limit of loratadine in plasma was $0.3 \mathrm{ng} / \mathrm{ml}$. The relationship between loratadine concentration in plasma and the peak area ratio of loratadine / IS was linear $\left(\mathrm{R}^{2} \geq 0.9945\right)$ in the range of $0.5-100 \mathrm{ng} / \mathrm{ml}$, and the intraand inter-day coefficient of variations $(\mathrm{CV})$ were $\leq 11.3 \%$. Mean extraction recoveries for loratadine and the IS were $87 \%$ and $91 \%$ respectively, whereas accuracy (relative recovery) ranged from $99 \%$ to $111 \%$ quality control samples and from $93 \%$ to $105 \%$ using back- calculated concentrations. The method was applied to assess the stability of loratadine under various conditions generally encountered in the clinical laboratory. Stability for processed samples (24 hours at room temperature, 48 hours $-20^{\circ} \mathrm{C}$ ) and unprocessed samples (24 hours at room temperature, 12 weeks $-20^{\circ} \mathrm{C}$ ) was $\geq 94 \%$.

Key words: Loratadine, Metoclopramide, Human plasma, HPLC 


\section{INTRODUCTION}

Loratadine (CAS: 79794-75-5), Ethyl-4-(8-Chloro-5,6-dihydro-11H- benzo [5,6]cyclohepta[1,2b]pyridin-11-ylidene)-1-piperidinecarboxylate, is a second-generation $\mathrm{H} 1$ histamine antagonist, closely related to tricyclic antidepressants. It is used in treating various kind of allergies and chronic idiopathic urticaria ${ }^{1,2}$. Plasma protein binding for loratadine and its active metabolite, desloratadine, are $98 \%$ and $75 \%$, respectively. Following $10 \mathrm{mg}$ oral dose, loratadine is rapidly absorbed with peak plasma concentrations $\left(C_{\max }\right)$ of $4.64 \mathrm{ng} / \mathrm{ml}$ for loratadine and $5.25 \mathrm{ng} / \mathrm{ml}$ for desloratadine, with time to maximum concentration $\left(\mathrm{T}_{\max }\right)$ of $1.3 \mathrm{hrs}$ and $2.5 \mathrm{hrs}$ for loratadine and desloratadine, respectively ${ }^{3}$.

Several high-performance liquid chromatography (HPLC) methods have been reported for determination of loratadine in biological samples ${ }^{4-6}$. HPLC-UV methods showed a limit of quantitation (LOQ) of $\geq 33 \mathrm{ng} / \mathrm{ml}^{4}$. An HPLC-fluorescence method showed lower limit of quantification of $0.5 \mathrm{ng} / \mathrm{ml}$. However, sample preparation required extraction with organic solvent followed by back extraction with diluted phosphoric acid ${ }^{5}$. Finally, LCMS/MS methods have been used to improve the detection limits of loratadine in human plasma ${ }^{7-13}$.

In this paper, we describe a precise and accurate LCMS/MS method for determination of loratadine level in human plasma. The method is based on liquid extraction and uses $1.0 \mathrm{ml}$ plasma sample. The method was fully validated and successfully used to monitor stability of loratadine in human plasma for samples.

\section{MATERIALS AND METHOD}

\section{Apparatus}

Liquid chromatography was performed on tandem mass spectrometric (LC-MS/MS) system consisting of a Water Alliance 2695 separation module equipped with Micromass Quattro micro API bench-top triple quadruple mass spectrometer interfaced with a Z-spray electrospray ionization (ESI) source. Analysis was performed on reversed phase Atlantis $\mathrm{dC}_{18}$ column $(2.1 \mathrm{x}$ $100 \mathrm{~mm}, 3 \mu \mathrm{m})$ protected by guard column Symmetry $\mathrm{C}_{18}(3.9$ x $20 \mathrm{~mm}, 5 \mu \mathrm{m})$, Waters Corporation, Milford, MA, USA. MassLynx software (Ver 4.0) working under Microsoft Window $\mathrm{XP}$ professional environment was used to control the instrument parameters and for data acquisition.

\section{Chemical and reagents}

All reagents were of analytical grade unless stated otherwise. Loratadine and metoclopramide standards (purity $\geq 98 \%$ ) and tert-butyl methyl ether were obtained from Sigma-Aldrich, United 
Kingdom. Formic acid and acetonitrile (HPLC grade) were purchased from Fisher Scientific, NJ. USA. HPLC grade water was prepared by reverse osmosis and was further purified by passing through Synergy (Millipore, Bedford, MA, USA). Drug-free human plasma was obtained from the blood bank of King Faisal Specialist Hospital \& Research Centre (KFSHRC) Riyadh, Saudi Arabia.

\section{Chromatographic conditions}

The mobile phase consisted of $0.4 \%$ formic acid $(\mathrm{pH}=3.0$, adjusted with formic acid) and acetonitrile (20:80, v:v) and was delivered at a flow rate of $0.25 \mathrm{ml} / \mathrm{min}$. The analysis was carried out at room temperature under isocratic condition. ESI was operated in the positive-ion mode at a capillary voltage of $4.0 \mathrm{kV}$ and a cone voltage of $30 \mathrm{~V}$. Nitrogen was used as nebulizing and desolvation gas at a flow rate of 50 and $600 \mathrm{~L} / \mathrm{hr}$, respectively. Argon was used as the collision gas at a pressure of $1.28 \times 10^{-3}$ mbar. The optimum collision energy for loratadine and the IS was 25 $\mathrm{eV}$. The ion source and the desolvation temperatures were maintained at $120{ }^{\circ} \mathrm{C}$ and $350{ }^{\circ} \mathrm{C}$, respectively. Loratadine and IS were detected using positive ion multiple reaction monitoring $(\mathrm{MRM})$ mode at the following transitions of mass to charge $(\mathrm{m} / \mathrm{z}): 383.4 \rightarrow 337.2$ and $299.8 \rightarrow 226.9$ for loratadine and IS, respectively.

\section{Preparation of standard and quality control samples}

Stock solutions $(1 \mathrm{mg} / \mathrm{ml})$ of loratadine and metoclopramide (internal standard, IS) were prepared in acetonitrile. They were diluted to produce working solutions of $100 \mathrm{ng} / \mathrm{ml}$ of loratadine in plasma and $1.0 \mu \mathrm{g} / \mathrm{ml}$ of IS in acetonitrile. Calibration curve standards (nine concentrations) in the range of $0.5-100 \mathrm{ng} / \mathrm{ml}$ were prepared in human plasma. Four quality control (QC) samples $(0.5$, $1.0,50$, and $90 \mathrm{ng} / \mathrm{ml}$ ) were also prepared in human plasma. $1.0 \mathrm{ml}$ aliquots from each flask were transferred into teflon-lined, screw-capped, borosilicate glass 12 x 100 mm culture tubes (Fisher Scientific Co., Fairlawn, NJ, USA), stored at $-20^{\circ} \mathrm{C}$, and used for assay validation purposes.

\section{Sample preparation}

Aliquots of $1.0 \mathrm{ml}$ of blank plasma, calibration curves, or QC samples culture tubes were allowed to equilibrate to room temperature (RT). To each tube, $180 \mu \mathrm{l}$ of the IS working solution was added and the mixture was vortexed for 20 seconds. After the addition of $5 \mathrm{ml}$ of tert-butyl methyl ether, the mixture was vortexed again for 2 min and then centrifuged at room temperature for 20 min at $4700 \mathrm{rpm}$. The clear supernatant organic layer was carefully transferred into clean tube and dried under gentle stream of nitrogen at $40{ }^{\circ} \mathrm{C}$, and the residue was reconstituted with $80 \mu 1$ of acetonitrile and transferred to an auto-sampler vial. Ten $\mu$ l were injected into the system with a run time of $3 \mathrm{~min}$. 


\section{Stability studies}

Three QC samples (concentration 1.5, 50, and $90 \mu \mathrm{g} / \mathrm{ml}$ ) were used for stability studies: five aliquots of each QC sample were extracted and immediately analyzed (baseline), five aliquots were allowed to stand on the bench-top for 24 hours at room temperature before being processed and analyzed, five aliquots were stored at $-20{ }^{\circ} \mathrm{C}$ for 12 weeks before being processed and analyzed, and five aliquots were processed and stored at room temperature for 24 hours or at -20 ${ }^{\circ} \mathrm{C}$ for 48 hours before analysis. Fifteen aliquots of each QC sample were stored at $-20{ }^{\circ} \mathrm{C}$ for 24 hours. They were then taken out of freezer and left to completely thaw unassisted at room temperature. Five aliquots of each sample were extracted and analyzed and the rest were returned to $-20{ }^{\circ} \mathrm{C}$ for another 24 hours. The cycle was repeated three times.

\section{Method validation}

The LCMS/MS method was validated according to standard procedures described in the US Food and Drug Administration (FDA) bioanalytical method validation guidance ${ }^{14}$. The validation parameter included specificity, linearity, accuracy, precision, recovery, and stability.

\section{RESULTS AND DISCUSSION}

\section{Optimization of chromatographic conditions}

Optimal experimental conditions consisted of a mobile phase composed of $0.4 \%$ formic acid ( $\mathrm{pH}=3$, adjusted with formic acid) and acetonitrile (20:80, v:v) and delivered at a flow rate of 0.25 $\mathrm{ml} / \mathrm{min}$. Under these conditions loratadine and IS were well separated and detected within a 3 minute run. The retention times of the IS and the loratadine were around 1.53 and $2.33 \mathrm{~min}$, respectively. Figure 1 depicts total ion current (TIC) and multiple reaction monitoring (MRM) chromatograms of loratadine and metoclopramide (IS) mixture extracted from plasma. 

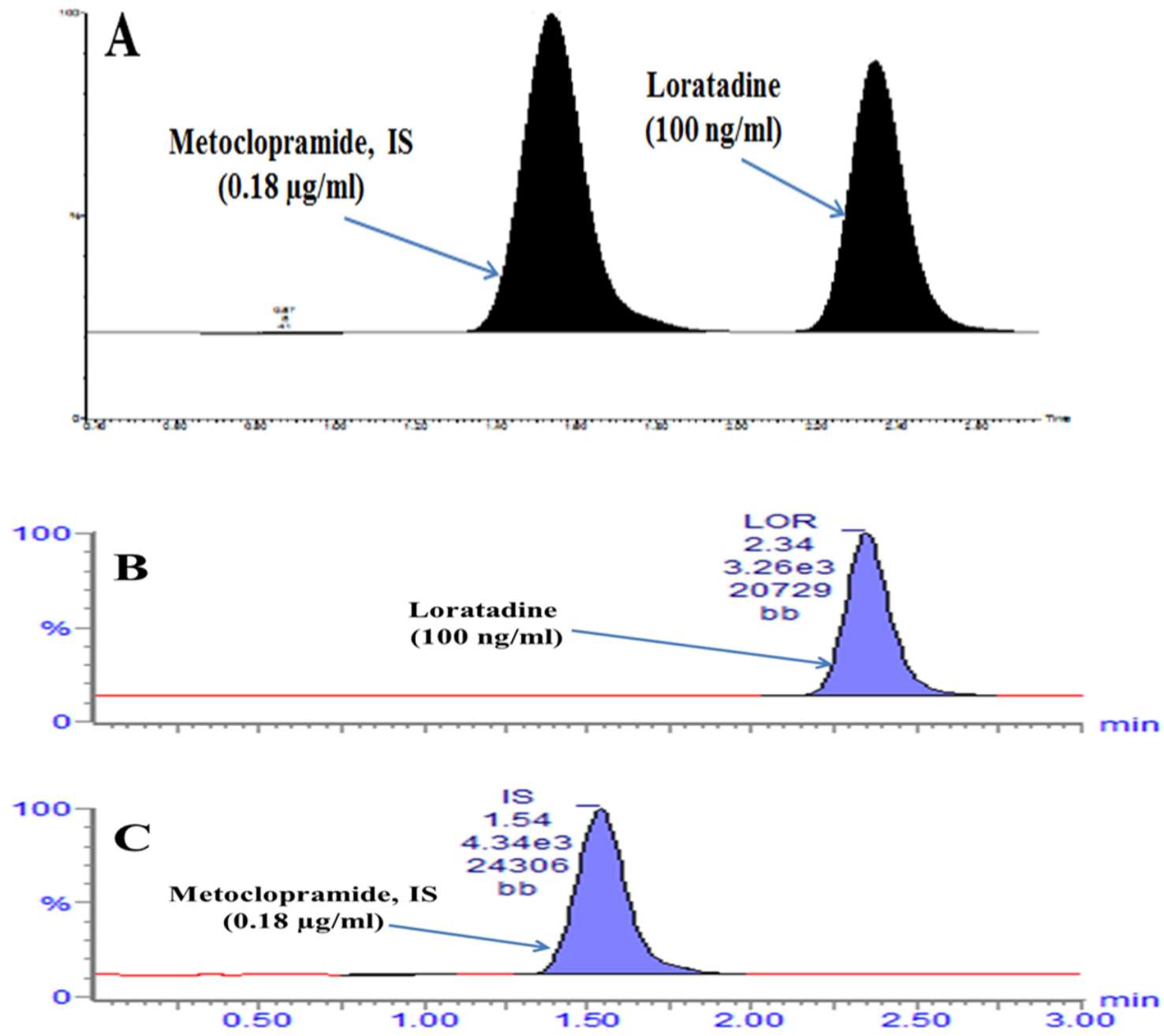

Figure 1: Caption: TIC and MRM chromatograms of loratadine and metoclopramide (IS) extracted from plasma.

Legend: (A) Total Ion Current (TIC) chromatogram standard mixture containing loratadine and metoclopramide. (B) Multiple reaction monitoring (MRM) chromatogram of loratadine (100 $\mathrm{ng} / \mathrm{ml}$ ), and (C) MRM chromatogram of metoclopramide (IS) $0.18 \mu \mathrm{g} / \mathrm{ml}$.

The ESI source was operated at optimum capillary voltage of $4.0 \mathrm{kV}$ and cone voltage of $30 \mathrm{~V}$. The optimum collision energy for loratadine and the IS was $25 \mathrm{eV}$. The ion source and the desolvation temperatures were maintained at $120^{\circ} \mathrm{C}$ and $350{ }^{\circ} \mathrm{C}$, respectively

\section{Specificity}

We screened six batches of blank human plasma and nine frequently used medications (acetaminophen, ascorbic acid, aspirin, caffeine, diclofenac, ibuprofen, nicotinic acid, omeprazole, and ranitidine) for potential interference. No interference was found in plasma and none of the drugs co-eluted with loratadine or the IS. Figure 2 depicts a representative MRM chromatogram of blank plasma used in the preparation of standard and QC samples. 


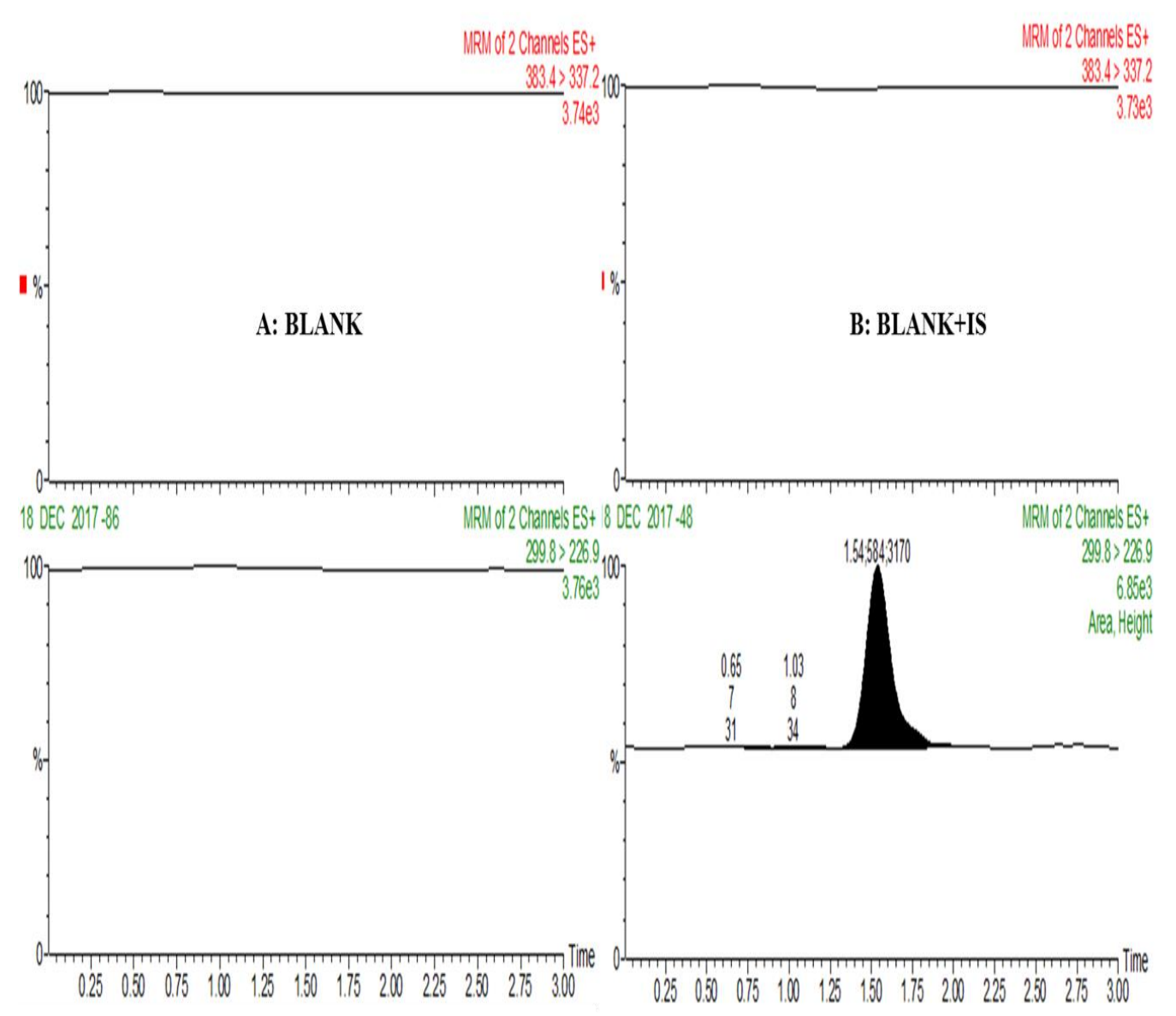

Figure 2: Caption: MRM chromatogram of blank and IS spiked plasma.

\section{Limit of detection \& quantification and linearity}

The limit of quantification, defined as the lowest concentration on the calibration curve that can be determined with acceptable precision and accuracy (i.e., coefficient of variation and bias $\leq 20 \%$ ), was $0.5 \mathrm{ng} / \mathrm{ml}$. The limit of detection (signal to noise-ratio $\geq 3$ ) was $0.3 \mathrm{ng} / \mathrm{ml}$. Linearity of loratadine was evaluated by analyzing ten curves of nine (plus zero) standard concentrations prepared in human plasma. Figure 3 depicts an MRM chromatogram of loratadine at lowest limit of quantification extracted from plasma. Mean (SD) of slope, intercept, and coefficient of determination $\left(\mathrm{R}^{2}\right)$ of the ten curves were 0.9980 (0.0006), - 0.0030 (0.0047), and $0.9960(0.0015)$, respectively. The suitability of the calibration curves was confirmed by back-calculating the concentrations of loratadine (Table 1). All back-calculated concentrations were well within the acceptable limits. 


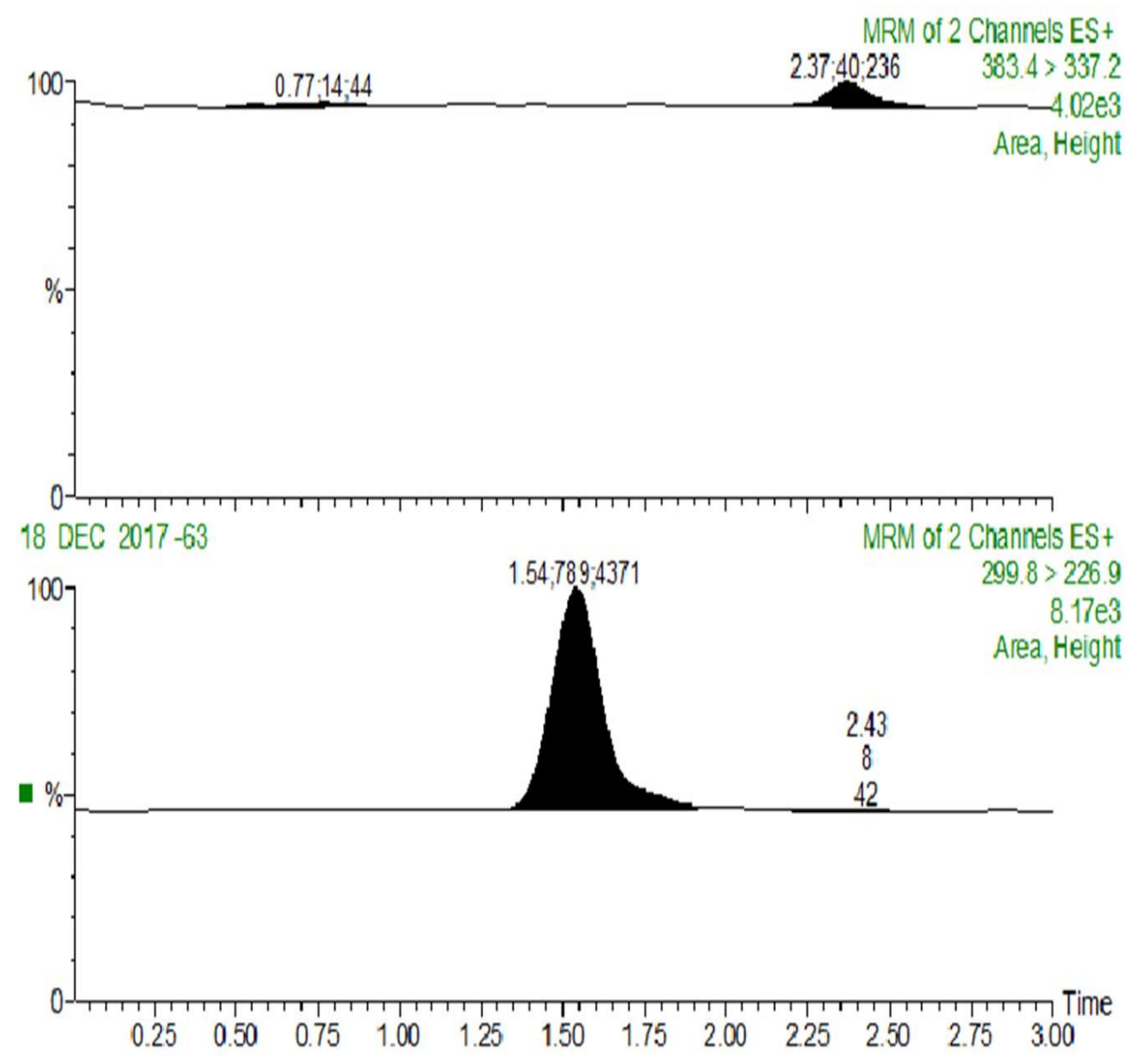

Figure 3: MRM chromatogram of loratadine at lowest limit of quantification extracted from plasma.

Table 1: Back-calculated loratadine concentrations from ten calibration curves

\begin{tabular}{llll}
\hline $\begin{array}{l}\text { Nominal level } \\
(\mathbf{n g} / \mathbf{m l})\end{array}$ & $\begin{array}{l}\text { Measured level } \\
(\mathbf{n g} / \mathbf{m l})\end{array}$ & $\mathbf{C V}(\%)$ & Bias (\%) \\
\cline { 2 - 2 } & Mean (SD) & & \\
\hline 0.5 & $0.53(0.07)$ & 14.0 & 6.0 \\
1.0 & $1.05(0.08)$ & 7.4 & 5.0 \\
2.0 & $2.34(0.22)$ & 9.2 & 17 \\
5.0 & $5.24(0.44)$ & 8.5 & 4.8 \\
10 & $9.32(0.43)$ & 4.6 & -6.8 \\
20 & $18.84(0.86)$ & 4.6 & -5.8 \\
40 & $39.96(3.55)$ & 8.9 & -4.0 \\
80 & $78.87(4.43)$ & 5.6 & 1.4 \\
100 & $100.89(3.25)$ & 3.2 & 0.9 \\
\hline
\end{tabular}

$\mathrm{SD}$, standard deviation. CV, standard deviation divided by mean measured concentration $\times 100$.

Bias $=($ mean measured concentration - nominal concentration divided by nominal concentration $)$ $\times 100$. 


\section{Precision and bias (inaccuracy)}

The intra-day and inter-day precision and bias of the method were evaluated by analyzing four QC concentrations $(0.5,1.5,50$, and $90 \mathrm{ng} / \mathrm{ml})$. Intra-day precision and bias $(\mathrm{n}=10)$ ranged from $7.5 \%$ to $11.3 \%$ and from $2.0 \%$ to $10.5 \%$, respectively. Inter-day precision and bias were determined over three different days $(n=20)$ and ranged from $8.1 \%$ to $10.3 \%$ and from $-2.0 \%$ to $7.3 \%$, respectively. The results are summarized in Table 2. Figure 4 depicts MRM chromatograms of loratadine quality control samples.
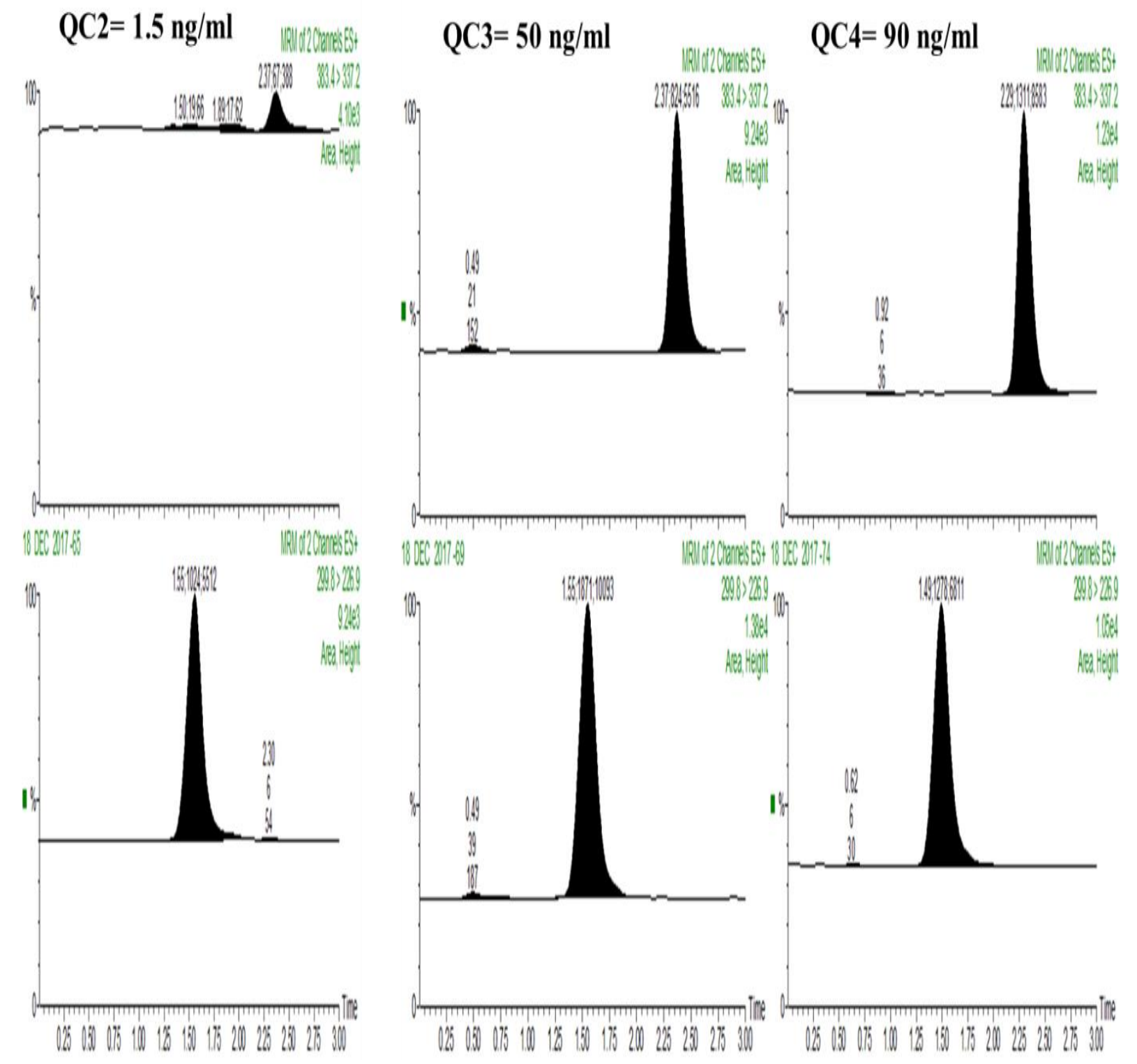

Figure 4: MRM chromatograms of loratadine quality control samples extracted from plasma 
Table 2: Intra and inter-day precision and bias of loratadine assay

\begin{tabular}{llll}
\hline $\begin{array}{l}\text { Nominal } \\
\text { level }(\mathbf{n g} / \mathbf{m l})\end{array}$ & $\begin{array}{l}\text { Measured level }(\mathbf{n g} / \mathbf{m l}) \\
\text { Mean (SD) }\end{array}$ & CV (\%) & Bias (\%) \\
Intra-day $(\mathrm{n}=10)$ & & \\
\hline 0.5 & $0.51(0.06)$ & 11.3 & 2.0 \\
1.5 & $1.58(0.17)$ & 10.5 & 5.3 \\
50 & $55.27(4.17)$ & 7.5 & 10.5 \\
90 & $95.38(8.17)$ & 8.6 & 6.0 \\
Inter-day $(\mathrm{n}=20)$ & & \\
0.5 & $0.49(0.05)$ & 9.3 & -2.0 \\
1.5 & $1.51(0.15)$ & 10.3 & 0.7 \\
50 & $53.66(4.33)$ & 8.1 & 7.3 \\
90 & $92.09(7.80)$ & 8.5 & 2.3 \\
\hline
\end{tabular}

SD, standard deviation. CV, standard deviation divided by mean measured concentration x100.

Bias $=($ mean measured concentration - nominal concentration divided by nominal concentration $)$ $\times 100$.

\section{Recovery}

Extraction recovery of loratadine was assessed by direct comparison of peak areas from plasma and mobile phase samples, using five replicates for each of four QCs $(0.5,1.5,50$, and $90 \mathrm{ng} / \mathrm{ml})$. Similarly, the recovery of the IS was determined by comparing peak areas of the IS in five aliquots of human plasma spiked with $180 \mu \mathrm{l}$ of $1.0 \mu \mathrm{g} / \mathrm{ml}$ in acetonitrile IS solution with the peak areas of equivalent samples prepared in the mobile phase. The results are presented in Table 3. Mean recovery of loratadine and the IS were $87 \%$ and $91 \%$, respectively.

Table 3: Recovery of loratadine and the internal standard from $1.0 \mathrm{ml}$ human plasma

\begin{tabular}{llll}
\hline Concentration (ng/ml) & $\begin{array}{c}\text { Human plasma } \\
\text { *Mean (SD) }\end{array}$ & $\begin{array}{l}\text { Mobile phase } \\
\text { *Mean (SD) }\end{array}$ & Recovery (\%) \\
\hline Loratadine & & & \\
0.5 & $72(7)$ & $91(7)$ & 79 \\
1.5 & $161(17)$ & $194(14)$ & 83 \\
50 & $3675(181)$ & $4105(89)$ & 90 \\
90 & $7347(124)$ & $7556(251)$ & 97 \\
IS $(0.18 \mu \mathrm{g} / \mathrm{ml})$ & $4413(531)$ & $4853(221)$ & 91 \\
\hline
\end{tabular}

Mean peak area (standard deviation), $\mathrm{n}=5$. Recovery was calculated as mean peak area in human plasma divided by mean peak area in mobile phase x 100 .

\section{Matrix effect}

Matrix effect was evaluated by comparing the peak area response of pre and post extracts of loratadine at four concentrations $(0.5,1.5,50$, and $90 \mathrm{ng} / \mathrm{ml})$ and the IS at $0.18 \mu \mathrm{g} / \mathrm{ml}$. Twenty five extracted blank plasma samples were reconstituted using $80 \mu \mathrm{l}$ of acetonitrile containing equal 
amount of loratadine and IS. Matrix effect was calculated as ion suppression (Table 4). Mean ion suppressed effect was measured as $-11.4 \%$ for loratadine and $-14.4 \%$ for the IS.

Table: 4 Human plasma matrix effect on loratadine and the internal standard

\begin{tabular}{llll}
\hline $\begin{array}{l}\text { Concentration } \\
\text { (ng/ml) }\end{array}$ & $\begin{array}{l}\text { Pre-treatment plasma } \\
\text { Mean (SD) }\end{array}$ & $\begin{array}{l}\text { Post-treatment plasma } \\
\text { Mean (SD) }\end{array}$ & $\begin{array}{l}\text { Matrix Effect } \\
(\%)\end{array}$ \\
\hline Loratadine & & & -14.1 \\
0.5 & $99(10)$ & $85(11)$ & \\
1.5 & $218(13)$ & $184(12)$ & -15.4 \\
50 & $4345(223)$ & $4105(196)$ & -5.6 \\
90 & $9219(497)$ & $8243(659)$ & -10.6 \\
IS $(180)$ & $6154(140)$ & $5268(27)$ & -14.4 \\
\hline
\end{tabular}

Matrix Effect $(\%)=$ Mean peak area (post-treatment) - mean peak area (pre-treatment) divided by mean peak area (pre-treatment) x100. $\mathrm{N}=5$.

\section{Robustness}

The robustness of the current assay was evaluated by slightly altering proportions of acetonitrile ( \pm $2.0 \%)$, and the $\mathrm{pH}$ of the mobile phase $( \pm 0.2)$. No significant changes were observed.

\section{Stability}

Loratadine and IS stability in processed and unprocessed plasma samples was investigated using three QCs $(1.5,50$, and $90 \mathrm{ng} / \mathrm{ml})$. Loratadine in processed samples was found to be stable for 24 hours at room temperature $(\geq 94 \%)$ and for 48 hours at $-20{ }^{\circ} \mathrm{C}(\geq 94 \%)$. Loratadine in unprocessed plasma samples was stable for at least 24 hours at room temperature ( $\geq 94 \%), 12$ weeks at $-20{ }^{\circ} \mathrm{C}(\geq 94 \%)$, and after three freeze-and thaw cycles $(\geq 94 \%)$. Table 5 summarizes the results of stability studies.

Table 5: Stability for loratadine in human plasma

\begin{tabular}{|c|c|c|c|c|c|c|c|}
\hline \multicolumn{8}{|l|}{ Stability (\%) } \\
\hline \multirow[t]{3}{*}{ Nominal level (ng/ml) } & \multicolumn{2}{|c|}{ Unprocessed } & \multicolumn{2}{|c|}{ Processed } & \multicolumn{3}{|c|}{ Freeze-Thaw Cycle } \\
\hline & $24 \mathrm{hrs}$ & 12 wks & $24 \mathrm{hrs}$ & $48 \mathrm{hrs}$ & 1 & 2 & 3 \\
\hline & RT & $20^{\circ} \mathrm{C}$ & RT & $20^{\circ} \mathrm{C}$ & & & \\
\hline 1.5 & 99 & 101 & 94 & 94 & 94 & 94 & 94 \\
\hline 50 & 94 & 94 & 101 & 95 & 102 & 101 & 95 \\
\hline 90 & 101 & 104 & 100 & 95 & 97 & 100 & 95 \\
\hline
\end{tabular}

Stability $(\%)=$ mean measured concentration $(\mathrm{n}=5)$ at the indicated time divided by mean measured concentration $(n=5)$ at baseline $x$ 100. Spiked plasma samples were processed and analyzed immediately (baseline, data not shown), after 24 hours at room temperature (24 hrs RT), or after freezing at $-20^{\circ} \mathrm{C}$ for 12 weeks $\left(12 \mathrm{wks},-20^{\circ} \mathrm{C}\right)$, or processed and then analyzed after storing for 24 hours at room temperature $(24 \mathrm{hrs}, \mathrm{RT})$ or 48 hours at $-20{ }^{\circ} \mathrm{C}\left(48 \mathrm{hrs},-20{ }^{\circ} \mathrm{C}\right)$. Freeze-thaw (FT), samples were frozen at $-20{ }^{\circ} \mathrm{C}$ and thaw at RT. 


\section{CONCLUSION}

The described LC-MS/MS assay for the determination of loratadine in human plasma is simple sensitive, specific, precise and accurate; making it suitable for therapeutic drug monitoring and pharmacokinetic analysis. It requires $1.0 \mathrm{ml}$ plasma and 3 minutes run time. It was successfully applied to monitor stability of loratadine under various conditions encountered in the clinical laboratories.

\section{REFERENCES}

1. Kassem N, Roman 1, Gural R, Dver JG, Robillard N. Effects of loratadine (SCH 29851) in suppression of histamine-induced Skin wheals. Ann Allergy 1988; 60: 505-507.

2. Barenholtz AH, McLeod. Loratadine: a nonsedating antihistamine with once-daily dosing. Dalian Institute of Chemical Physics 1989; 23: 445-450.

3. Kosoglou T, M Salfi, Lim JM, Batra VK, Cayen MN, Affrime MB. Evaluation of the pharmacokinetics and electrocardiographic pharmacodynamics of loratadine with concomitant administration of ketoconazole or cimetidine. Br J Clin Pharmacol 2000; 50(6): 581-589.

4. Villacampa J, Alcantar F, Rodriguez JM, Morales JM, Herrera J, et al. Pharmacokinetic properties of single-dose loratadine and ambroxol alone and combined in tablet formulations in healthy men. Clin Ther. 2003; 8: 2225-2232.

5. Pavalache G, Dorneanu V. Validation of an analytical method based on high performance liquid chromatography for determination of loratadine in pharmaceutical preparations and biological environments. Farmacia 2011; 59 (2): 200-207.

6. Xu XJ1, Shang EX, Qiu FR, Mao GG, Xiang BR. Determination of loratadine in human plasma by HPLC with fluorescence detector and study on its bioavailability. Yao Xue Xue Bao 2004; 39(2): 123-12.

7. Zhong D, Blume H. HPLC-determination of loratadine and its active metabolite descarboethoxyloratadine in human plasma. Pharmazie 1994; 49: 736-739.

8. D. Zhang, J. He, M. Yang, H.-C. Liu. Determination of loratadine in human plasma by LC-MS/MS and its application in bioequivalence study. Chinese Journal of New Drugs 2013; 22(13): 1560-1565.

9. Vlase L1, Imre S, Muntean D, Leucuta SE. Determination of loratadine and its active metabolite in human plasma by high-performance liquid chromatography with mass spectrometry detection. Pharm Biomed Anal 2007; 44(3): 652-7. 
10. Naidong W1, Addison T, Schneider T, Jiang X, Halls TD. A sensitive LCMS/MS method using silica column and aqueous-organic mobile phase for the analysis of loratadine and descarboethoxy-loratadine in human plasma. J Pharm Biomed Anal 2003; 8-32(4-5): 609-617.

11. Nagwa A. S., Eslam M.S., Erini S.H. and Sarah H.A. Determination of lortatadine in human plasma by liquid chromatography tandem mass spectrometry (LCMS/MS) and its pharmacokinetic application. Int J Pharm Sci Res 2014; 1: 102.

12. Laurian V. V., Silvia I., Dana M., Sorin L. Determination of loratadine and its active metabolite in human plasma by high-performance liquid chromatography with mass spectrometry detection. J of Pharm and Biomed Anal 2007; 44(3): 652-657.

13. Li W1, Doherty J, Moench P, Flarakos J, Tse FL. Li, Wenkui and Doherty, John and Moench, Paul and Flarakos, Jimmy and Tse. LC-MS/MS bioanalysis of loratadine (Claritin) in dried blood spot (DBS) samples collected by subjects in a clinical research study. J Chromatogr B Analyt Technol Biomed Life Sci. 2015; 1; 983-984.

14. Bioanalytical Method Validation, Food and Drug Administration, Centre for Drug Evaluation and Research (CDER), Nov. 2017.

\section{AJPTR is}

- $\quad$ Peer-reviewed

- bimonthly

- Rapid publication

Submit your manuscript at: editor@ajptr.com 